\title{
Water Saving and Cost Analysis of Large-Scale Implementation of Domestic Rain Water Harvesting in Minor Mediterranean Islands
}

\author{
Alberto Campisano * (1), Giuseppe D'Amico and Carlo Modica \\ Department of Civil Engineering and Architecture, University of Catania, Viale Andrea Doria, 6, \\ 95125 Catania, Italy; info.giuseppedamico@gmail.com (G.D.-A.); cmodica@dica.unict.it (C.M.) \\ * Correspondence: acampisa@dica.unict.it; Tel.: +39-095-738-2730
}

Received: 20 October 2017; Accepted: 22 November 2017; Published: 25 November 2017

\begin{abstract}
This paper describes a novel methodology to evaluate the benefits of large-scale installation of domestic Rain Water Harvesting (RWH) systems in multi-story buildings. The methodology was specifically developed for application to small settlements of the minor Mediterranean islands characterized by sharp fluctuations in precipitation and water demands between winter and summer periods. The methodology is based on the combined use of regressive models for water saving evaluation and of geospatial analysis tools for semi-automatic collection of spatial information at the building/household level. An application to the old town of Lipari (Aeolian islands) showed potential for high yearly water savings (between $30 \%$ and $50 \%$ ), with return on investment in less than 15 years for about $50 \%$ of the installed RWH systems.
\end{abstract}

Keywords: rainwater harvesting; minor islands; water saving; cost analysis; surrogate models; geospatial analysis

\section{Introduction}

Several countries of the Mediterranean are involved in finding proper solutions to problems related to the management of scarce water resources under the concurrent increase in water demands. The growing use of water in urban areas pushes cities and water managers to look for alternative sources of renewable water.

Problems associated with water scarcity are very sharp in urban contexts of minor islands, where the water availability is normally limited by the small size of river catchments. Further difficulties in water supply management of minor Mediterranean islands are associated with the high fluctuations of the population (and water demand) between spring/summer and autumn/winter seasons due to the incoming/outgoing touristic fluxes.

During the last decades, non-conventional water supply based on the use of water tankers and/or desalination has contributed in a major way to meet drinking water demands in several archipelagos of the Mediterranean Sea (including, among others, the Aeolian islands, the Pelagian islands, and Cyprus). However, because of the high operational costs, the financial sustainability of such water sources in the medium to long term remains highly questionable [1].

In the search for alternative water sources, Rain Water Harvesting (RWH) has been acknowledged as a valid approach to reduce drinking water consumption in urban areas [2-4]. In particular, several literature studies developed in various countries point out the high potential of domestic RWH systems to meet non-potable water demands in private and public buildings [4-7]. Typical RWH systems consider rainwater reclamation from building rooftops, storage within a tank, and use of the harvested rainwater for a number of non-potable indoor uses (e.g., flushing of toilets, laundry, etc.) and outdoor uses (e.g., garden irrigation, car washing, etc.) [8-10]. 
The quantification of water saving benefits associated with the implementation of domestic RWH has been carried out broadly at the scale of the single-family household [11-14], but also with reference to multi-story/multi-family buildings (i.e., the collected rainwater is shared within the building) $[3,14,15]$. Much emphasis has been placed on the financial issues of the system implementation $[2,11,15,16]$. The financial viability of single RWH systems has been assessed using various approaches, including comparative analysis with other water supply strategies $[17,18]$. Methods based on the use of undersized tanks for low water demand conditions have also been explored to obtain an affordable payback period of the investments [19]. However, although large efforts have been spent over the decades to evaluate the benefits of RWH at the scale of a single installation, little attention has been paid to exploring the water saving potential derived from the implementation of RWH at larger spatial scales (e.g., district or city levels). One of the main reasons for this knowledge gap is probably the lack of reliable and computationally cheap methods for obtaining general validity for the systematic evaluation of large-scale implementation scenarios. In fact, such an evaluation requires detailed information on a range of site-specific parameters (e.g., building characteristics, type of dwellers, type of water demands, etc.) whose values have a significant impact on the system performance $[8,20]$. Early recent examples of methods used to estimate domestic RWH benefits from the household level include the coupled use of water saving evaluators and geospatial analysis tools for semi-automatic characterization of building characteristics in urban areas $[6,10]$. However, the available methods have been developed assuming operational schemes of RWH that are valid for single-family/single-household installations only. In addition, the sensitivity of rainfall and demand seasonal variations on the system performance has not been explored exhaustively.

The objective of this paper is to evaluate the potential benefits of large-scale implementation of domestic RWH as an alternative water supply approach for non-potable use in buildings of urban settlements of minor islands of the Mediterranean. A novel methodology was developed to evaluate the water saving performances of multi-story/multi-family RWH systems for toilet flushing use. The methodology combines the use of non-dimensional surrogate regressive models for water saving evaluation at the building level and the use of geospatial databases for archiving building/household information through classification routines of high quality imagery in urban contexts. The methodology was applied to the old town of Lipari (the largest municipality of the homonymous Aeolian island), which shows intra-annual patterns of precipitation and water demand characterized by sharp variations between wet and dry seasons.

\section{Methods}

\subsection{Model Framework}

Among the design parameters of RWH systems, the size of the rainwater tank is probably the most important [21].

In the past years, much research effort has been made to identify the optimal size of the rainwater tank. Available methodologies typically combine the results of models for the evaluation of the water saving and the cost of the system for a set of tank sizes. Models based on the water balance simulation of the tank have been used with large success due to their ability to appropriately describe rainfall and water demand dynamics in the long term [21]. The evaluation of large-scale RWH implementation projects introduces uncertainty due to the spatial variability of buildings and population-related characteristics, as well as of precipitation and water demand [22]. As a consequence, the application of water balance models for each household/building of the area under study is often an unpractical option, as it would require very high computational efforts.

A possibility to overcome this problem may be provided by the increase in the computational resources, for instance through the use of grid/cloud-based computing techniques [23]. Alternatively, simplified approaches have been proposed in the literature by References [24,25], 
who performed the simulation of a reduced number of typical demand scenarios and/or selected "equivalent" buildings representative of all building types in the study area. However, such approaches do not eliminate the existing uncertainty, thus requiring the provision of a robust sensitivity analysis of the results [6].

More recently, Reference [10] dealt with this issue, and proposed a methodology to overcome the computational impact associated with the recurrent use of water balance models. The methodology is based on the development of surrogate models for the accurate evaluation of RWH system performance based on the results of dimensionless water balance simulations. A similar approach was used in this paper, through the adaptation of the model by Reference [10] to the analysis of RWH schemes under scenarios characterized by multi-family/multi-story buildings with high seasonal water demand fluctuation during the year.

The model tracks the dimensionless water balance of the tank using the Yield-After-Spillage (YAS) algorithm as a tank release rule $[10,21]$, through the numerical solution of the following equations:

$$
\begin{gathered}
v_{t}=v_{t-1}+q_{t}-y_{t}-o_{t} \\
y_{t}=\min \left\{\begin{array}{c}
d_{t} \\
v_{t-1}
\end{array}\right. \\
o_{t}=\max \left\{\begin{array}{c}
v_{t-1}+\frac{R_{t}}{R}-s \\
0
\end{array}\right.
\end{gathered}
$$

where the following dimensionless variables are considered:

$v_{t}=\frac{V_{t}}{A \cdot R}($ dimensionless volume in store at time $t)$

$v_{t-1}=\frac{V_{t-1}}{A \cdot R}$ (dimensionless volume in store at time $t-1$ )

$q_{t}=\frac{Q_{t}}{A \cdot R}$ (dimensionless tank inflow at time $\left.t\right)$

$y_{t}=\frac{Y_{t}}{A \cdot R}$ (dimensionless yield from the tank at time $t$ )

$o_{t}=\frac{O_{t}}{A \cdot R}$ (dimensionless tank overflow at time $\left.t\right)$

$d_{t}=\frac{D_{t}}{A \cdot R}$ (dimensionless toilet water demand at time $\left.t\right)$

The previous dimensionless variables are obtained by normalization to $A \cdot R$ of the volumes in store $V_{t}\left(\mathrm{~m}^{3}\right)$ and $V_{t-1}\left(\mathrm{~m}^{3}\right)$, the tank inflow $Q_{t}=A \cdot R_{t}\left(\mathrm{~m}^{3}\right)$, the yield $Y_{t}\left(\mathrm{~m}^{3}\right)$, the overflow $O_{t}\left(\mathrm{~m}^{3}\right)$, as well as of the demand $D_{t}\left(\mathrm{~m}^{2}\right)$, with $A\left(\mathrm{~m}^{3}\right)$ being the rooftop catchment area for rainwater collection. Assuming the daily time scale to be adopted for the water balance analysis [26], $R(\mathrm{~m})$ is the average daily rainfall during the whole simulation period (e.g., 30 years).

The daily time scale resolution of Equations (1)-(3) requires the availability of long-term series of daily precipitation $R_{t}$ and water demands $D_{t}$ for toilet flushing as input information representing the available rainwater and consumption patterns in the building. While values of $R_{t}$ are usually provided by local meteorological offices, the expected daily demands $D_{t}$ for toilet flushing at the building level can be estimated as [10]:

$$
D_{t}=n_{d} \cdot n_{f t} \cdot F
$$

where $n_{d}$ is the number of dwellers in the building, $n_{f t}$ is the number of toilet flushes per capita per day $t$, and $F\left(\mathrm{~m}^{3}\right)$ is the volume of the toilet cistern (volume of the flush). Values of $n_{d}$ can be estimated as the ratio between the building total floor surface area and the average per capita living surface (net surface area in $\mathrm{m}^{2}$ attributed to each dweller).

Under the availability of daily patterns of precipitation and water demand for toilet flushing, the behavior of the rainwater tank can be studied, based on the following two dimensionless parameters [21]:

$$
s=\frac{S}{A \cdot R} \text { (storage fraction; } S\left[\mathrm{~m}^{3}\right] \text { is the rainwater tank capacity) }
$$




$$
d=\frac{D}{A \cdot R} \text { (demand fraction; } D\left[\mathrm{~m}^{3}\right] \text { is the average daily toilet demand in the building) }
$$

\subsection{Surrogate Regressive Models for Water Saving Evaluation}

The described dimensionless approach has the advantage of allowing the analysis of the results of the tank water balance simulations as a function of the dimensionless parameters of storage $(s)$ and demand $(d)$ fractions.

The results of the non-dimensional simulations provide the water saving performance of the RWH system for toilet flushing use in the generic building for each year $n$ of the whole simulation period:

$$
W S_{n}=\frac{\sum_{t=1}^{365} y_{t}}{\sum_{t=1}^{365} d_{t}} \cdot 100[\%]
$$

Obtained yearly values of $W S_{n}$ can be elaborated to evaluate water saving values corresponding to prefixed yearly reliability levels $f$ (frequency of exceedance) (e.g., $f=0.9$ means that the corresponding value of water saving has been achieved for at least $90 \%$ of the years). For all of the simulations, water saving values were calculated with reference to both the average value in the year and the dry (April-September) and wet (October-March) seasons, separately.

Simulations were run for scenarios of storage and demand fractions that include the whole range of variation of building types and of precipitation and water demand characteristics in the selected area. Simulation results were statistically elaborated in order to set up compact regression relationships that relate the water saving to $s, d$, and $f$. The developed relationships provide surrogate models of the water balance model used for the simulations, thus enabling quicker evaluation of the water saving performance of RWH installations at the desired spatial scale. Surrogate models were determined for the estimation of the average yearly water saving, as well as for the wet (October-March) and dry seasons, separately, using the following multiple-regression form:

$$
W S=\frac{x_{1} \cdot s}{x_{2}+s} \cdot d^{x_{3}} \cdot f^{x_{4}}[\%]
$$

where $x_{1}, x_{2}, x_{3}$, and $x_{4}$ are the calibration coefficients of the regressive models.

\subsection{Geospatial Database Setup}

Practical advantages of the described approach can be exploited if Equation (8) is used in combination with a database containing geospatial information concerning detailed building and population characteristics in the area of implementation.

Accordingly, a geodatabase was built for the systematic collection and archiving of information including buildings location, building type, height of the construction, number of stories, type of rooftop, roof collection catchment surface, etc. Data on the building characteristics were obtained through the combined use of techniques to process high resolution satellite imagery covering the study area and other internet available software tools (e.g., Google Street View). Surfaces of the building rooftops were determined by means of automatic extraction methods applied to the satellite images. Extraction of polygons associated with the identified rooftops was followed by post-processing through QGIS software (open source version 3.0), assuming each building polygon to coincide with the corresponding roof. Using the previous procedure, each identified rooftop was univocally associated with a single building. Only residential/private buildings were taken into account in the analysis, whereas rooftops of public buildings and industrial plants were excluded from calculations. Additionally, rooftops with extensions smaller than a selected threshold (e.g., car boxes, small shelters, etc.) were also excluded from the database. Acquired information was integrated with the data collected during a one-week-long survey in the study area with the objective of collecting data for buildings in those secondary streets which were not inspected through Google Street View software (Google Inc., Mountain View, CA, USA). Information on population distribution 
during the year in the study area was provided by the municipality. Such information was used to verify the global consistency of calculated values of $n_{d}$ for each "building" record in the area during the whole year.

\subsection{Cost-Benefit Analysis}

Cost-benefit analysis was carried out for the evaluation of the optimal tank size for each building. The considered cost items included capital, operational, and maintenance costs.

Capital $\operatorname{costs} C_{c}(€)$ were evaluated as:

$$
C_{c}=C_{s}+C_{i}
$$

where $C_{s}=\alpha+\beta \cdot S(€)$ is the cost of the system equipment (e.g., tank, pump, dual network pipes, etc.), with $\alpha(€)$ and $\beta\left(€ / \mathrm{m}^{3}\right)$ being coefficients usually provided by the tank manufactures, and $C_{i}$ is the installation cost $(€)$.

Operational costs include the annual cost of drinking water from mains $(€)$ used for toilet flushing when the rainwater tank is empty:

$$
C_{Y W M}=C_{W} \cdot\left(1-\frac{W S}{100}\right) \cdot D \cdot 365
$$

where $C_{W}\left(€ / \mathrm{m}^{3}\right)$ is the unit cost of drinking water. Operational costs also include the cost of energy $(€)$ for pumping rainwater from the tank to the toilets in the building:

$$
C_{Y E}=C_{E} \cdot \frac{W S}{100} \cdot D \cdot 365
$$

where $C_{E}\left(€ / \mathrm{m}^{3}\right)$ is the cost of energy per cubic meter of pumped rainwater.

Maintenance costs $(€)$ include pump replacement in case of failure, replacement of filters, and eventual costs for chlorination, and are calculated as a percent $\gamma$ of the capital costs:

$$
C_{M}=\gamma \cdot C_{c}
$$

The present value of the total costs (capital and recurring costs) was calculated according to the following relationship [27]:

$$
P V=C_{c}+\frac{(1+r)^{N}-1}{r \cdot(1+r)^{N}} \cdot\left[C_{Y W M}+C_{Y E}+C_{M}\right]
$$

where $r$ is the discount rate and $N$ is the number of years of the considered period of analysis (normally coinciding with the average life of the system).

Based on Equation (13), the minimization of $P V$ provides the optimal tank size:

$$
S^{o p t}=A \cdot R \cdot \sqrt{\frac{\left[(1+r)^{N}-1\right] \cdot x_{1} \cdot x_{2} \cdot 365 \cdot\left(C_{w}-C_{E}\right)}{100 \cdot \beta \cdot\left[(1+r)^{N} \cdot(r+\gamma)-\gamma\right]}} \cdot d^{0.5\left(1+x_{3}\right)} \cdot f^{0.5 \cdot x_{4}}-x_{2}
$$

In addition, for each building, the payback period $T$ of the investment was calculated as the ratio between capital costs and savings (from replaced drinking water):

$$
T=\frac{C_{c}}{C_{w} \cdot D \cdot 365 \cdot C_{Y W M} \cdot C_{Y E} \cdot C_{M}}
$$




\section{Case Study}

The described methodology was applied to the old town of Lipari, the largest municipality of the Aeolian archipelago in southern Italy.

The selected urban area has a total surface of about $0.45 \mathrm{Km}^{2}$, and hosts an average residential population in the wet season of about 6500 (with a minimum value of about 4000 in January) rising during spring/summer (average value 9900) up to a peak of about 12,000 in the month of August. The average population during the whole year is close to 8200 . Figure 1 shows the monthly pattern of the population in the area (normalized to the mean yearly value) as extrapolated by the data provided by the municipality (for residents) and by the census of year 2013. Additional data concerning the touristic fluxes in the island were provided by the Regional Department for Tourism, Sport, and Events [28].

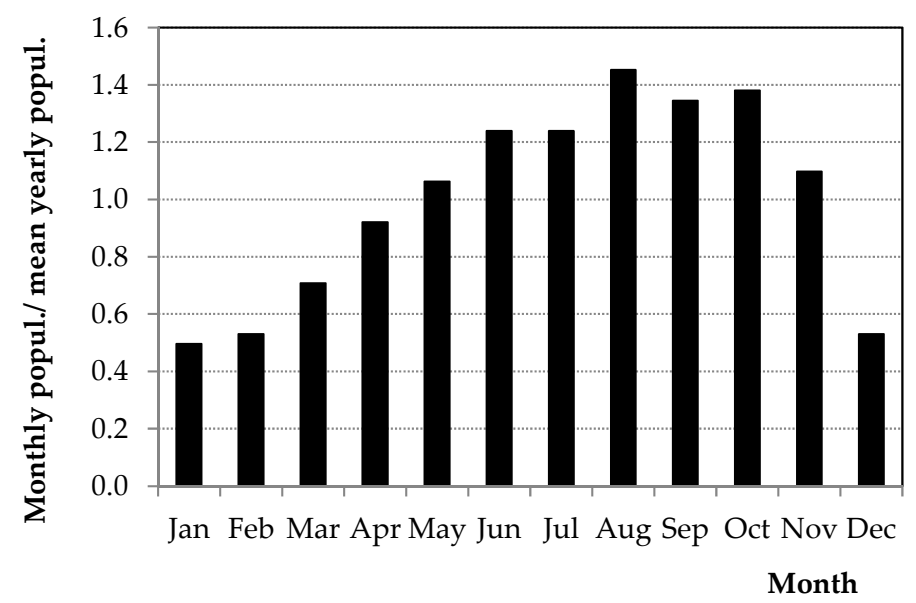

Figure 1. Monthly population normalized to mean yearly population for the island of Lipari.

Drinking water distributed in the selected area is supplied through mixing of water from tankers and desalination at an average cost of $C_{W}=4.17\left(€ / \mathrm{m}^{3}\right)$ throughout the year.

The area is characterized by a dense urban fabric with relatively small streets and buildings typically made of 1 to 3 stories that usually include commercial/craft activities/shops at the ground level and 1-6 single-family apartments on the upper floors. A few larger buildings (of more recent construction) are present in the northern part of the selected area. In many cases, each whole building belongs to the same owner, thus representing a single household (one single water meter installed) for the water distribution company. Similar to several urban areas in southern Italy, most (over 95\%) of the existing building covers are terraces with very small longitudinal slope (1-2\%), thus highlighting high potential for the exploitation of catchment surfaces for rainwater collection. Based on the characteristics of the building and on the described population patterns, the selected urban area of Lipari evidently represents a good test case for the application of the methodology proposed in this paper.

Results of the census of year 2013 in combination with data obtained from the direct survey in the area allowed to estimate the average values of the per capita living surface, thus enabling the evaluation of the number of dwellers for each building during the year. In absence of direct measurements of water demand for toilet flushing in the area of Lipari, six flushes per day were assumed as the per-capita daily pattern of $n_{f t}$, as suggested by the results of field experiments by Reference [29] concerning six households in Sicily. Additionally, low consumption toilet cisterns $(F=6 \mathrm{~L})$ were considered in the analysis for a prudent evaluation of the water saving from RWH implementation in the study area.

Precipitation data was provided by the Regional Agency for Water and Waste [30] and consisted of a 53-year-long series of daily precipitation recorded at Lipari meteorological station during the period of 1920-1994. Data showed a distribution of monthly precipitation typical of the Mediterranean 
islands (see Figure 2) with a wet semester in the period of October-March and a long dry summer period (with minimum precipitation values in July-August). The average total annual precipitation value over the 53 years is about $605 \mathrm{~mm}$.

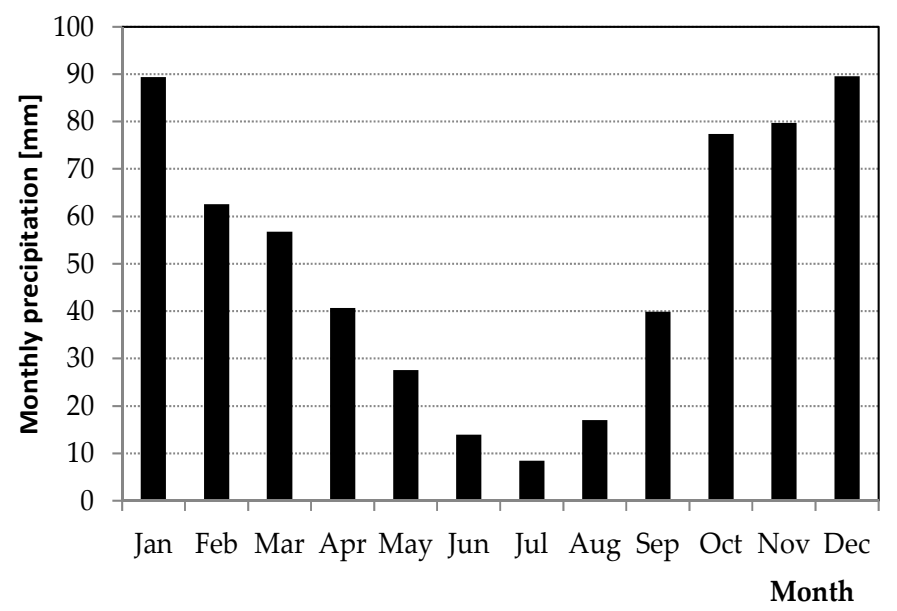

Figure 2. Monthly precipitation pattern. Lipari meteo-station (averages in the period 1920-1994).

\section{Results and Discussion}

\subsection{Water Balance Simulation Scenarios and Surrogate Models for Water Saving Evaluation}

The daily scale water balance of the rainwater tank was carried out for a number of scenarios that include different combinations of values of the storage fraction $s$ and of the demand fraction $d$. Combinations were identified based on the ranges of values for practical applications. In total, 25 dimensionless simulations were run that included values of $s$ between 0 and 40, and values of $d$ between 0.2 and 4.0. The use of such ranges allowed to take into account multi-story/multi-family buildings with rooftop catchment surfaces between 25 and $500 \mathrm{~m}^{2}$, runoff coefficients between 0.8 and 0.9, and 1-6 apartments per building. Moreover, as for the RWH system characteristics, such ranges included scenarios with $0.1-15 \mathrm{~m}^{3}$ rainwater tanks, 1-6 dwellers per apartment, 1-2 toilets with 6-9 liters toilet cisterns per apartment, and 5-8 flushes per capita per day. Simulations characterized by $d>1$ were considered to represent scenarios of high demand conditions (in summer periods), when the daily demand for toilet flushing in the building usually exceeds the collected rainfall volume.

The results of the water balance simulations were elaborated in order to evaluate the water saving performance of the RWH scheme for the whole year, and for the wet and dry seasons separately. In particular, yearly frequency distributions of water savings were calculated based on values of $W S$ for each year of the simulation period, with subsequent estimation of WS values corresponding to yearly reliabilities $f$ of $0.5,0.75$, and 0.9 .

The graphs of Figure 3 show, as an example, the results of the simulations for the average yearly and seasonal water savings for $f=0.9$. The graphs point out the typical (non-linear) increasing trend of the water saving curves as the value of the storage fraction increases (i.e., as the tank capacity increases and the rainfall volume decreases).

In agreement with previous results from the literature [7,9], the slope of the curves quickly reduces as $s$ increases, thus showing minor marginal benefits for values of $s$ larger than 20 for the whole year (Figure 3a) and 10 for the wet season (Figure 3b). Also, the decrease in demand fraction $d$ provides increasingly larger water saving benefits (minor demand for toilet flushing means improved possibility to fully satisfy it through rainwater). As expected, the water saving performance is maximized in the wet period (with values up to $70 \%$ for $d=1$ and $s=40$ ), while reduced performances (WS in the order of $30 \%$ ) are expected with the same value of $s$ in the dry season, due to reduced rainwater availability in the tank (Figure 3c). Relevantly, this result shows the impact of the local precipitation pattern 
(long dry summers with variable rainy winter periods) on the system performance in the studied area with relatively small values of WS for cases characterized by $d>1$.

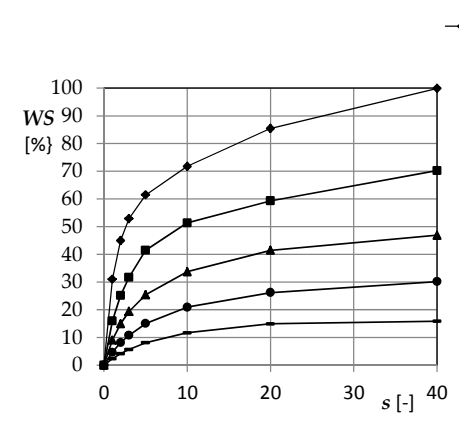

(a)$$
\bullet \mathrm{d}=0.2 \rightarrow \mathrm{d}=0.5 \rightarrow \mathrm{d}=1.0 \rightarrow \mathrm{d}=2.0 \rightarrow \mathrm{d}=4.0
$$

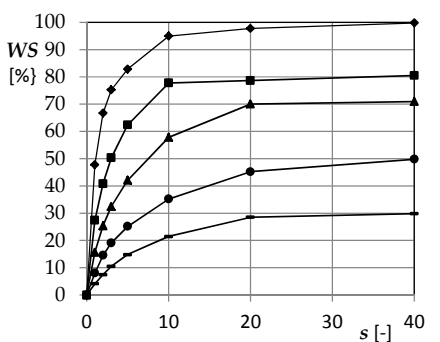

(b)

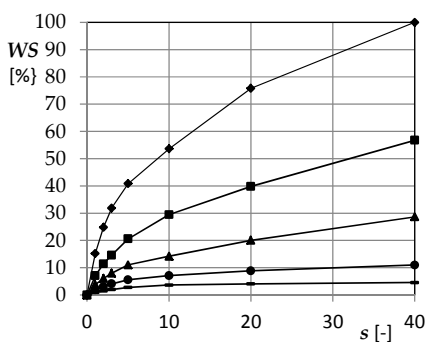

(c)

Figure 3. Water saving performance of the RWH system scheme for frequency of exceedance $f=0.9$ : (a) average yearly values; (b) average values for the wet season; (c) average values for the dry season.

The calibration of surrogate models (Equation (8)) provided the results summarized in Table 1. The table shows the high sensitivity of WS to the storage fraction $s$ (high variability of $x_{1}$ and $x_{2}$ ). Conversely, the highest sensitivity of WS to the demand fraction $d$ is obtained during the dry season (the highest value of exponent $x_{3}$ ). Importantly, the coefficient of determination $\left(R^{2}\right)$ and the mean absolute error (MAE) show a high degree of fitness, thus assuring reliable and accurate use of the obtained surrogate models for large-scale evaluation of the RWH system performance.

Table 1. Results of the calibration of the surrogate models.

\begin{tabular}{ccccccc}
\hline Validity & $x_{1}$ & $x_{2}$ & $x_{3}$ & $x_{\mathbf{4}}$ & $\boldsymbol{R}^{\mathbf{2}}$ & $\boldsymbol{M A E}$ \\
\hline Whole year & 45.547 & 3.052 & -0.492 & -0.264 & 97.04 & 3.60 \\
Wet season & 61.485 & 1.729 & -0.357 & -0.306 & 92.16 & 7.34 \\
Dry season & 32.461 & 6.997 & -0.715 & -0.383 & 97.44 & 2.53 \\
\hline
\end{tabular}

\subsection{Geodatabase Construction}

The geodatabase of the buildings in the area of study was populated with spatial information concerning the position of the buildings in the catchment, their typology (residential, public, commercial, etc.), the number of floors, as well as the surface area of the building rooftop.

The spatial resolution of the satellite imagery employed $(2 \mathrm{~m} \times 2 \mathrm{~m})$ led to a very accurate identification of the buildings. Preliminarily, 1301 buildings were identified within the boundaries of the selected area. A refinement step was carried out to eliminate the buildings with rooftop polygon surfaces larger than $500 \mathrm{~m}^{2}$. This step allowed to exclude industrial/commercial warehouses from the dataset, as they are not target buildings for the installation of domestic RWH systems. Moreover, information obtained through the use of Google Street View and the results of the local surveys were used to associate isolated rooftops smaller than $25 \mathrm{~m}^{2}$ (shed covers, car box roofs, etc.) with the closest/adjacent building (about $15 \%$ of the rooftops). Finally, a consistency check was carried out to verify each rooftop catchment to be associated with one building only, and vice versa. Globally, 984 buildings were archived in the structural geodatabase for the successive calculation of RWH potential in the selected area. Figure 4 shows a picture of the area under study with all of the building rooftops that were identified for the analysis.

Information stored in the geodatabase for each "building" record was completed with data concerning the expected number of dwellers and the estimated water demand for toilet flushing use in the building. 


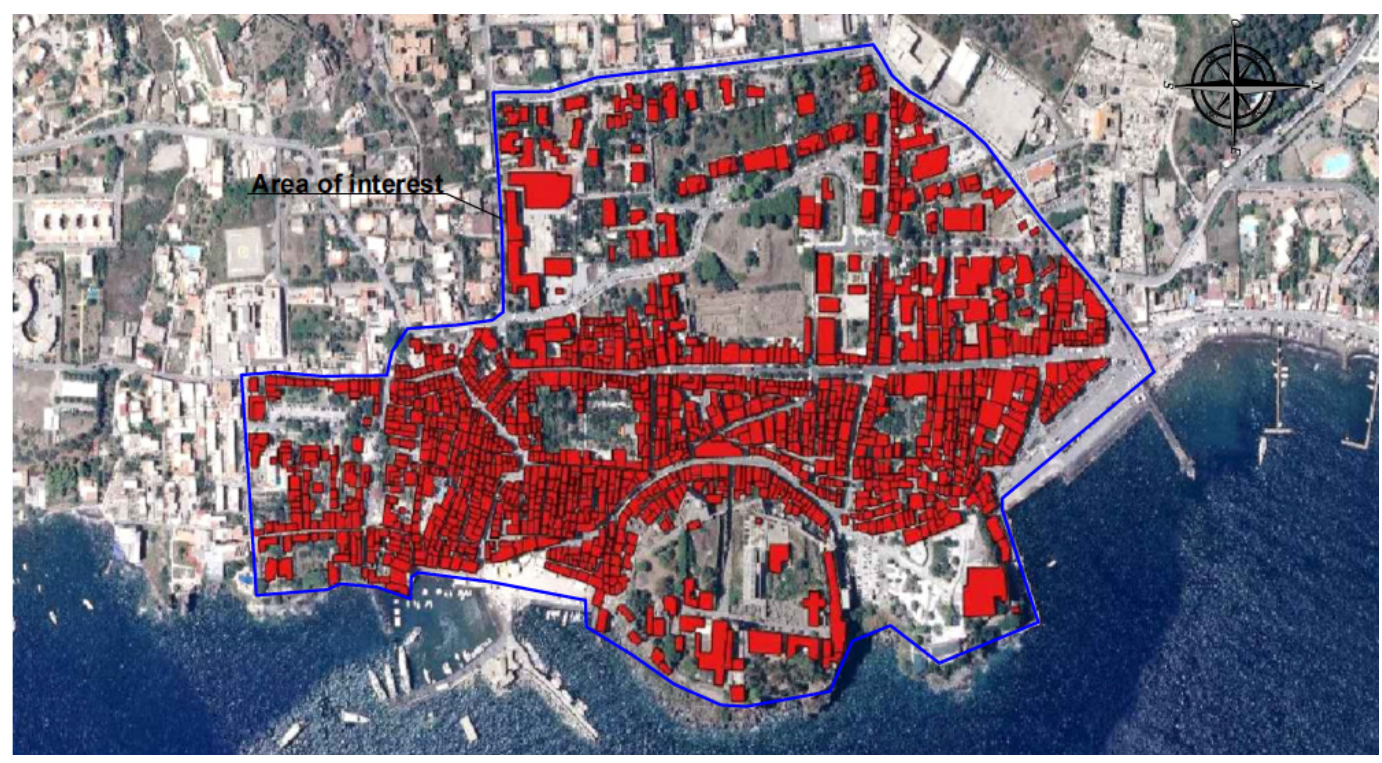

Figure 4. Area under study with identification of the buildings for RWH system installation.

Figure 5 shows the spatial variation of the water demand for toilet flushing use in the area for the wet (Figure 5a) and the dry (Figure 5b) seasons, respectively. The comparison between the figures shows the increase in water demand during spring/summer due to the growing population in the area. As expected, the larger water demand was obtained for the larger buildings in the northern outskirt.

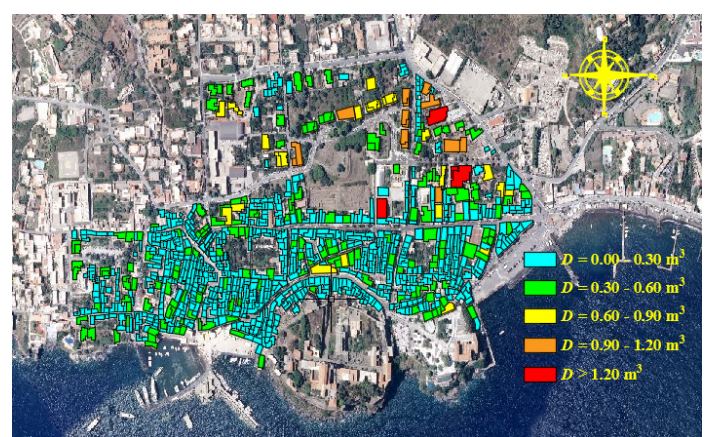

(a)

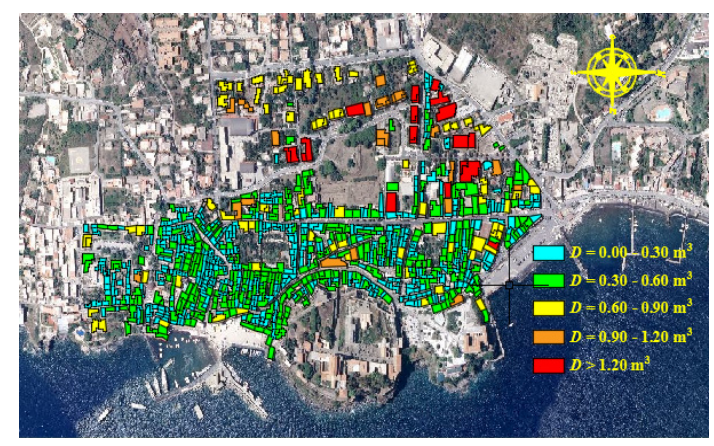

(b)

Figure 5. Spatial distribution of water demand for toilet flushing for: (a) wet season; (b) dry season.

Systematic evaluation of the optimal tank size for each building was carried out using Equation (14). Calculations were carried out, considering the values of $x_{1}, x_{2}, x_{3}$, and $x_{4}$ obtained for the whole year and considering $f=0.5$. Local values of cost parameters $\left.C_{W}=4.17\left(€ / \mathrm{m}^{3}\right]\right)$, and $C_{E}=0.02\left(€ / \mathrm{m}^{3}\right)$ were also assumed. Moreover, the official regional price list for public and private works was used to determine the values of $\gamma=0.02$, and $\beta=82.0\left(€ / \mathrm{m}^{3}\right)$ for all of the installations. The sensitivity of the results to parameters $r$ and $N$ was analyzed by applying Equation (14) for $r=3 \%$ and $r=6 \%$ and for values of $N$ between 15 and 25 years.

As an example of the results, Figure 6 shows the comparison between the distributions of the optimal tank sizes ( $r=3 \%$ ) for $N=15$ and $N=25$ years, respectively. Interestingly, a limited sensitivity of the results to $N$ is highlighted, with a prevalence of tank sizes in the range of $2-5 \mathrm{~m}^{3}$ irrespective of the value of $N$ used for the calculations. 


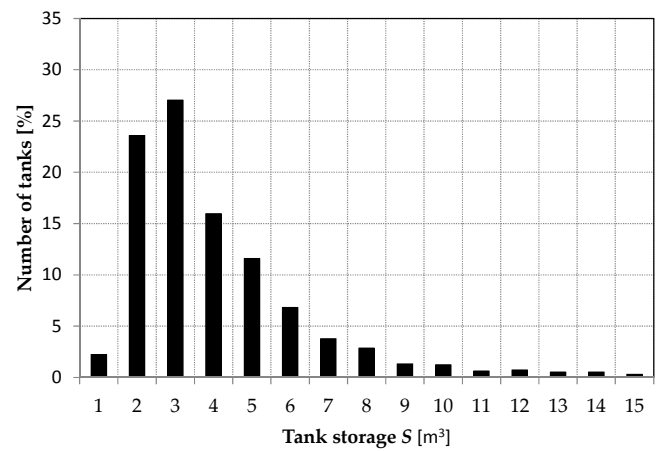

(a)

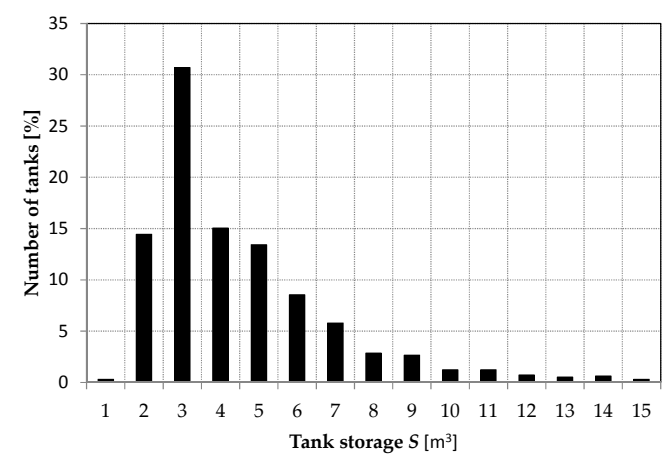

(b)

Figure 6. Frequency distribution of optimal tank sizes for $r=3 \%$ and for (a) $N=15$ years; (b) $N=25$ years.

\subsection{Water Saving Evaluation for the Area of Interest}

The application of the calibrated surrogate models to each record of the geodatabase provided the systematic (worksheet-based) evaluation of WS for all of the buildings.

Figure 7 reports the results of the application $(N=25, f=0.5$, and $r=3 \%)$, including the average yearly water saving, as well as the values of WS for the wet and dry seasons, respectively. Interestingly, the analysis of Figure 7a reveals that a very large part of the buildings (94\%) in the area may lead to average WS performance in the year between $30 \%$ and $50 \%$. The figure also shows water saving potential to decrease down to $10-30 \%$ for the dry period.

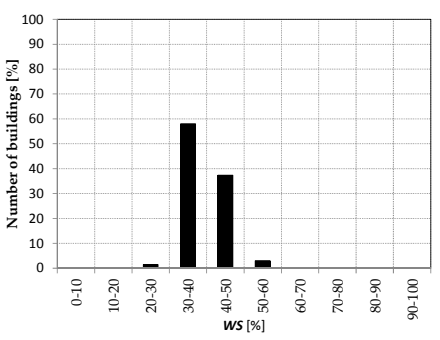

(a)

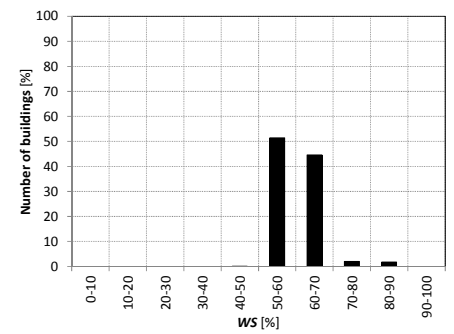

(b)

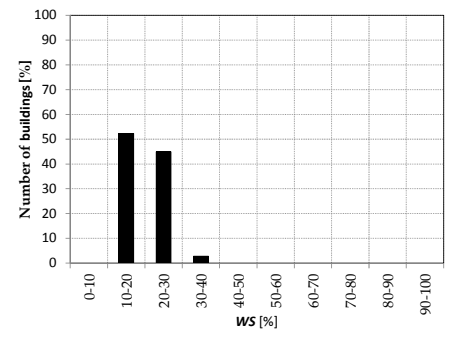

(c)

Figure 7. Obtained values of WS for the large-scale installation of RWH systems in the area under study $(N=25, f=0.5$, and $r=3 \%)$ : (a) average in the year; (b) wet season; (c) dry season.

The spatial variation of the obtained water saving for all of the considered buildings in the area is reported in Figure 8 for the wet and dry seasons, respectively.

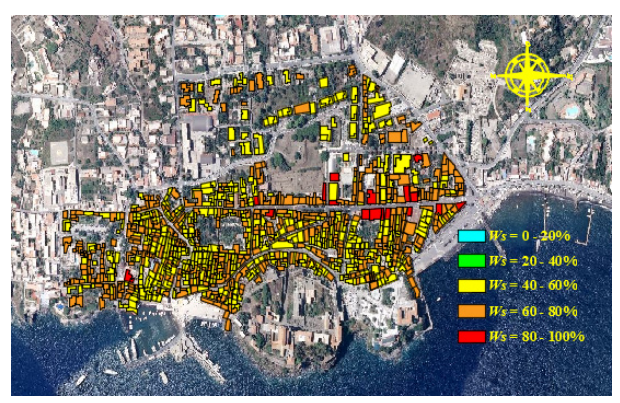

(a)

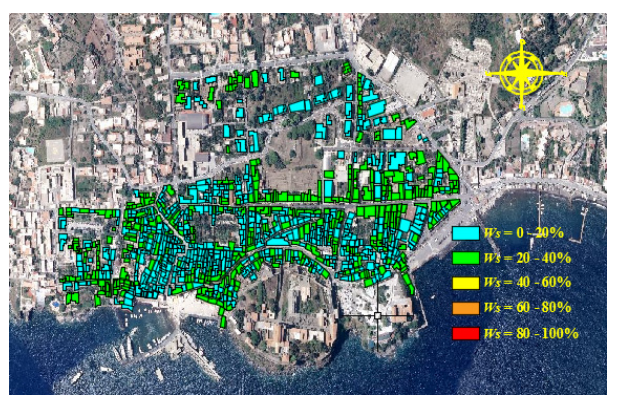

(b)

Figure 8. Spatial distribution of water saving for the different buildings $(N=25, f=0.5$, and $r=3 \%)$ for: (a) wet season; (b) dry season. 
The figure confirms the different value of water saving that can be obtained in the two periods due to the temporal rainfall pattern and to the different level of water demand associated with the wet and dry seasons, respectively (see Figure 5). In particular, in agreement with the results presented in Figure 3, the buildings characterized by lower demands usually provide the larger water saving performances.

The cost comparison between the RWH implementation scenario and the actual water supply scenario (tankers and desalination) deserves further discussion. An illustrative example of the comparison is shown in Figure 9. This figure points out the curve of $P V(€)$ as function of time for a typical 4-apartment building in Lipari $\left(A=160 \mathrm{~m}^{2}\right.$; average demand for toilet flushing $D=0.575 \mathrm{~m}^{3} /$ day; tank size $S=3 \mathrm{~m}^{3} ; f=0.5 ; N=25$ ) and for the two scenarios of discount rate $r=3 \%$ (Figure $9 \mathrm{a}$ ) and $r=6 \%$ (Figure $9 \mathrm{~b}$ ).

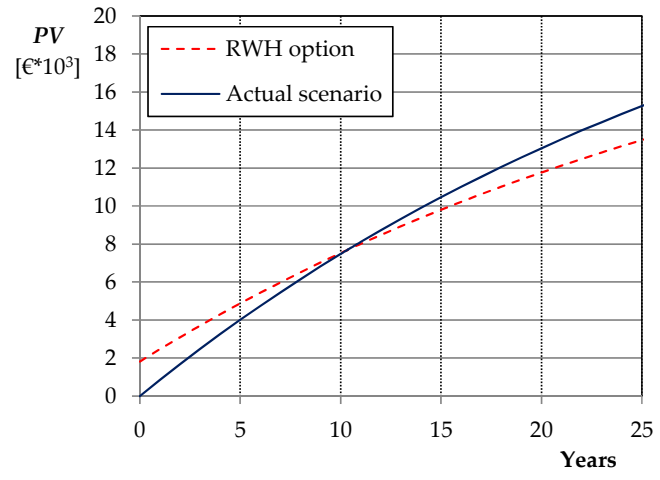

(a)

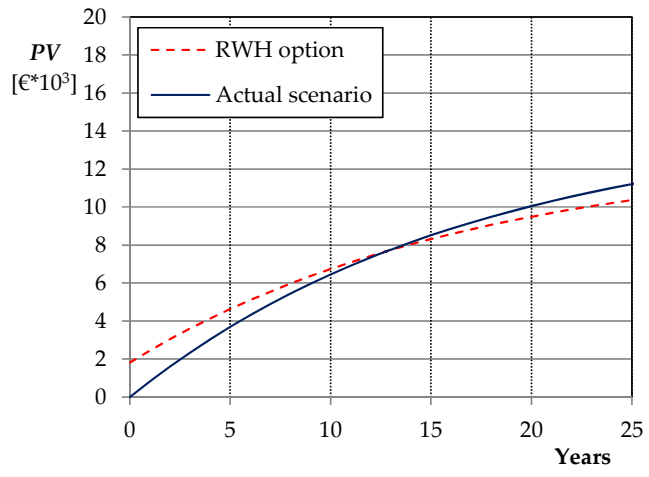

(b)

Figure 9. Curve of present value $P V$ for $A=160 \mathrm{~m}^{2} ; 4$-apartment building with average total daily demand for toilet flushing $D=0.575 \mathrm{~m}^{3} /$ day; $S=3 \mathrm{~m}^{3} ; f=0.5 ; N=25$, and for $(\mathbf{a}) r=3 \%$; (b) $r=6 \%$.

As expected, the curve relative to the RWH implementation option (dashed line) shows an initial step due to the cost of installation. However, yearly cumulative water savings due to the replacement of drinking water with rainwater for toilet flushing use results in the curve having a smaller slope in comparison to the curve representing the current scenario of water supply in the island (solid line). Interestingly, the system return on investment is achieved after about 10 years and 13 years for $r=3 \%$ and $r=6 \%$, respectively, after which the RWH option starts generating increasing profit up to the end of life of the installation.

Globally, the results of the evaluation of the payback period of the investment through the use of Equation (15) for each building of the area are summarized in Figure 10 for $f=0.5, N=25$, and $r=3 \%$. The figure points out that more than $85 \%$ of the installed systems would show payback periods smaller than 25 years and that about $50 \%$ of the installed systems falls in the range of $0-15$ years. More relevantly, the investment for about one fourth of the installed systems could be repaid in less than 10 years, thus representing the priority option for the community in the case of batch installation by successive steps.

Finally, it is underlined that the obtained results do not take into account of all aspects that may affect the economic impact of a large-scale implementation of RWH systems (e.g., water quality aspects). Therefore, further research efforts will be devoted in the future to include such aspects within the developed methodology. 


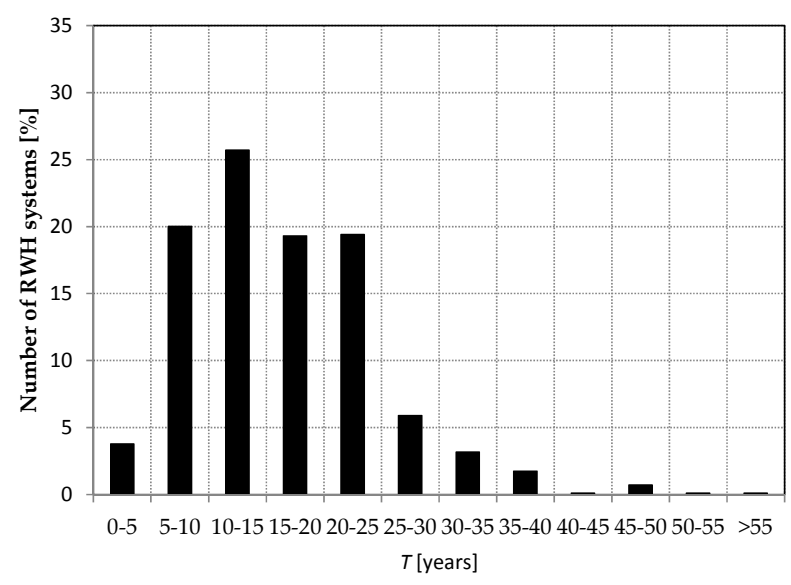

Figure 10. Distribution of payback periods of RWH installations in the area of interest (results are relative to $f=0.5, N=25$, and $r=3 \%$ ).

\section{Conclusions}

A novel methodology to evaluate the benefits of a large-scale installation of domestic RWH systems in multi-story urban buildings of minor islands was proposed in this paper.

The methodology was developed for specific application to minor Mediterranean islands that are characterized by large fluctuations in precipitation and water demands (due to touristic fluxes) between winter and summer periods. The methodology is based on the development of easy-to-use regressive models for water saving evaluation and their coupling with geospatial analysis tools for the collection of detailed building/household information on the urban area of study.

The methodology was applied to the old town of Lipari, the largest municipality of the homonymous Aeolian island, and showed large potential water saving benefits of RWH implementation in the area. Globally, the characteristics of 984 buildings were collected and archived in the geodatabase using information from high resolution satellite imagery which was integrated by information obtained through the use of Google Street View and the results of local surveys.

The systematic application of the developed regressive models to all of the buildings in the area showed average yearly water saving performances between $30 \%$ and $50 \%$. The comparison with the current water supply scenario in the island (tankers and desalination) pointed out the beneficial impact of RWH installation for toilet flushing use of harvested rainwater in the selected urban area. The cost-benefit evaluation of the large-scale installation scenario showed that about $50 \%$ of the RWH systems would provide payback periods in the range of $0-15$ years, and that about one fourth of the installed systems could be potentially repaid in less than 10 years.

Author Contributions: All the authors have contributed extensively to the work presented in this paper; A. Campisano and C. Modica conceived and designed the methodology and the used model; G. D'Amico collected data and performed the model simulations; all the authors have analyzed the data; A. Campisano and C. Modica wrote the paper.

Conflicts of Interest: The authors declare no conflict of interest.

\section{References}

1. Badiuzzaman, P.; McLaughlin, E.; McCauley, D. Substituting freshwater: Can ocean desalination and water recycling capacities substitute for groundwater depletion in California? J. Environ. Manag. 2017, 203, 123-135. [CrossRef] [PubMed]

2. Roebuck, R.M.; Oltean-Dumbrava, C.; Tait, S. Whole life cost performance of domestic rainwater harvesting systems in the United Kingdom. Water Environ. J. 2011, 25, 355-365. [CrossRef]

3. Rahman, A.; Dbais, J.; Imteaz, M. Sustainability of rainwater harvesting systems in multistory residential buildings. Am. J. Eng. Appl. Sci. 2010, 3, 889-898. [CrossRef] 
4. Campisano, A.; Butler, D.; Ward, S.; Burns, M.J.; Friedler, E.; DeBusk, K.; Fisher-Jeffes, L.N.; Ghisi, E.; Rahman, A.; Furumai, H.; et al. Urban rainwater harvesting systems: Research, implementation and future perspectives. Water Res. 2017, 115, 195-209. [CrossRef] [PubMed]

5. Ward, S.; Memon, F.A.; Butler, D. Performance of large building rainwater harvesting systems. Water Res. 2012, 46, 5127-5134. [CrossRef] [PubMed]

6. Rostad, N.; Foti, R.; Montalto, F.A. Harvesting rooftop runoff to flush toilets: Drawing conclusions from four major U.S. cities. Resour. Conserv. Recycl. 2016, 108, 97-106. [CrossRef]

7. Palla, A.; Gnecco, I.; Lanza, L.G. Non-dimensional design parameters and performance assessment of rainwater harvesting systems. J. Hydrol. 2011, 401, 65-76. [CrossRef]

8. Ghisi, E. Parameters influencing the sizing of rainwater tanks for use in houses. Water Resour. Manag. 2010, 24, 2381-2403. [CrossRef]

9. Melville-Shreeve, P.; Ward, S.; Butler, D. Rainwater harvesting typologies for UK houses; a multi criteria analysis of system configurations. Water 2016, 8, 129. [CrossRef]

10. Campisano, A.; Lupia, F. A dimensionless approach for the urban scale evaluation of domestic rainwater harvesting systems for toilet flushing and garden irrigation. Urban Water J. 2017, 14, 883-891. [CrossRef]

11. Sample, D.J.; Liu, J. Optimizing rainwater harvesting systems for the dual purposes of water supply and runoff capture. J. Clean. Prod. 2014, 75, 174-194. [CrossRef]

12. Campisano, A.; Gnecco, I.; Modica, C.; Palla, A. Designing domestic rainwater harvesting systems under different climatic regimes in Italy. Water Sci. Technol. 2013, 67, 2511-2518. [CrossRef] [PubMed]

13. Burns, M.J.; Fletcher, T.D.; Duncan, H.P.; Hatt, B.E.; Ladson, A.R.; Walsh, C.J. The performance of rainwater tanks for stormwater retention and water supply at the household scale: An empirical case study. Hydrol. Process. 2015, 29, 152-160. [CrossRef]

14. Domenèch, L.; Saurí, D. A comparative appraisal of the use of rainwater harvesting in single and multi-family buildings of the Metropolitan Area of Barcelona (Spain): Social experience, drinking water savings and economic costs. J. Clean. Prod. 2011, 19, 598-608. [CrossRef]

15. Liaw, C.H.; Tsai, Y.L. Optimum storage volume of rooftop rainwater harvesting systems for domestic use. J. Am. Water Resour. Assoc. 2004, 40, 901-912. [CrossRef]

16. Khastagir, A.; Jayasuriya, N. Investment evaluation of rainwater tanks. Water Resour. Manag. 2011, 25, 3769-3784. [CrossRef]

17. Morales-Pinzón, T.; Rieradevall, J.; Gasol, C.M.; Gabarrell, X. Modelling for economic cost and environmental analysis of rainwater harvesting systems. J. Clean. Prod. 2015, 87, 613-626. [CrossRef]

18. Loubet, P.; Roux, P.; Loiseau, E.; Bellon-Maurel, V. Life cycle assessments of urban water systems: A comparative analysis of selected peer-reviewed literature. Water Res. 2014, 67, 187-202. [CrossRef] [PubMed]

19. Sanches Fernandes, L.F.; Terêncio, D.P.S.; Pacheco, F.A.L. Rainwater harvesting systems for low demanding applications. Sci. Total Environ. 2015, 529, 91-100. [CrossRef] [PubMed]

20. Mitchell, V. How important is the selection of computational analysis method to the accuracy of rainwater tank behavior modelling? Hydrol. Process. 2007, 21, 2850-2861. [CrossRef]

21. Fewkes, A.; Butler, D. Simulating the performance of rainwater collection systems using behavioural models. Build. Serv. Eng. Res. Technol. 2000, 21, 99-106. [CrossRef]

22. Lash, D.; Ward, S.; Kershw, T.; Butler, D.; Eaames, M. Robust rainwater harvesting: Probabilistic tank sizing for climate change adaptation. J. Water Clim. Chang. 2014, 5, 526-539. [CrossRef]

23. Burns, M.J.; Fletcher, T.D.; Walsh, C.J.; Ladson, A.R.; Hatt, B.E. Flow-regime management at the urban land-parcel scale: Test of feasibility. J. Hydrol. Eng. 2015, 20. [CrossRef]

24. Farreny, R.; Morales-Pinzón, T.; Guisasola, A.; Tayà, C.; Rieradevall, J.; Gabarrell, X. Roof selection for rainwater harvesting: Quantity and quality assessments in Spain. Water Res. 2011, 45, 3245-3254. [CrossRef] [PubMed]

25. Belmeziti, A.; Coutard, O.; de Gouvello, B. A new methodology for evaluating potential for potable water savings (PPWS) by using rainwater harvesting at the urban level: The case of the municipality of Colombes (Paris region). Water 2013, 5, 312-326. [CrossRef]

26. Campisano, A.; Modica, C. Appropriate resolution timescale to evaluate water saving and retention potential of rainwater harvesting for toilet flushing in single houses. J. Hydroinform. 2015, 17, 331-346. [CrossRef] 
27. Mearig, T.; Coffe, N.; Morgan, M. Life Cycle Cost Analysis Handbook, 1st ed.; State of Alaska-Department of Education \& Early Development, Alaska School Facilities: Juneau, AK, USA, 1999.

28. Regional Department for Tourism, Sport, and Events. Available online: http://www.regione.sicilia.it/ turismo/web_turismo/ (accessed on 15 September 2017).

29. Campisano, A.; Modica, C. Experimental investigation on water saving by the reuse of washbasin grey water for toilet flushing. Urban Water J. 2010, 7, 17-24. [CrossRef]

30. Regional Agency for Water and Waste. Available online: http:/ /www.osservatorioacque.it/ (accessed on 15 September 2017).

(C) 2017 by the authors. Licensee MDPI, Basel, Switzerland. This article is an open access article distributed under the terms and conditions of the Creative Commons Attribution (CC BY) license (http://creativecommons.org/licenses/by/4.0/). 